\title{
Long-Term Application of Remote Sensing Chlorophyll Detection Models: Jordanelle Reservoir Case Study
}

\author{
Carly Hyatt Hansen', Gustavious P. Williams², Zola Adjei² \\ ${ }^{1}$ Department of Civil and Environmental Engineering, University of Utah, Salt Lake City, USA \\ ${ }^{2}$ Department of Civil and Environmental Engineering, Brigham Young University, Provo, USA \\ Email: gus.williams@byu.edu
}

Received 23 January 2015; accepted 10 February 2015; published 15 February 2015

Copyright (C) 2015 by authors and Scientific Research Publishing Inc.

This work is licensed under the Creative Commons Attribution International License (CC BY). http://creativecommons.org/licenses/by/4.0/

(c) (i) Open Access

\begin{abstract}
Algae blooms pose a threat to water quality by depleting oxygen during decomposition and also cause other issues with water quality and water use. Algae biomass is traditional monitored through field samples analyzed for chlorophyll-a, a pigment present in all algae. Field sampling can be time- and cost-intensive, especially in areas that are difficult to access and provides only limited spatial coverage. Estimations of algal biomass based on remote sensing data have been explored over the past two decades as a supplement to information obtained from limited field samples. We use Landsat data to develop and demonstrate seasonal remote sensing models, a relatively recent method, to evaluate spatial and temporal algae distributions for the Jordanelle Reservoir, located in north-central Utah. Remote sensing of chlorophyll as a monitoring and analysis method can provide a more spatially complete representation of algae distribution and biomass; information that is difficult to obtain using point samples.
\end{abstract}

\section{Keywords}

Chlorophyll Detection, Remote Sensing, Water Quality

\section{Introduction}

Algae blooms pose a threat to water quality and lake or reservoir ecosystems by depleting oxygen during decomposition, releasing toxins, and reducing sunlight penetration depth. Blooms can also place additional burdens on water treatment plants, produce odors, and limit recreational use. Lake managers traditionally monitor algae biomass through field samples which are analyzed for chlorophyll-a, a pigment present in all algae. Moni- 
toring campaigns may be conducted by different organizations, have significant time lapses, and have limited spatial extent because of the expense and effort required to collect field samples. Remote sensing using Landsat imagery provides data every 16 days (clouds permitting), and can provide retrospective estimates of reservoir behavior as far back as 1984 [1]. The objective of this study was to examine long-term trends in surface algal biomass through the use of remote sensing estimation algorithms. Landsat measures surface reflectance in several different wavelengths and the spectral response can be correlated to the concentration of chlorophyll pigment present at the surface. Seasonal models significantly improve this correlation as they account for seasonal algal succession and the differences in pigmentation across changing algal populations [2]-[4]. The use of remote sensing approaches to study algal distributions both temporally and spatially has the potential to provide useful information about reservoir behavior. Remote sensing data allow study of algae distributions both spatially (throughout the entire body of water rather than limited field sample locations) and temporally (over the life of a reservoir and throughout the growing season, not just for a single day). As noted, Landsat data is available from 1984 with collections every 16 days. Previous work has shown that historical data collections, even if they are close in time but not coincident with satellite overpasses, can be used to develop robust estimation models that can be applied to the Landsat record [5]-[7].

\section{Jordanelle Background}

Jordanelle is a large reservoir of about 3300 acres on the Provo River with a capacity of approximately 360,500 acre-feet, and a maximum depth of 292 feet [8]. The dam was completed and the reservoir completely filled in 1994. It is used for a wide range of purposes, extending from recreation, irrigation, industrial, and municipal consumption. Jordanelle Reservoir was built to regulate the downstream Deer Creek Reservoir, also on the Provo River. Deer Creek Reservoir is a major water supply reservoir, so the Jordanelle water quality is of concern to water managers. Jordanelle is located in the Wasatch Mountains east of Salt Lake City, Utah (Figure 1).

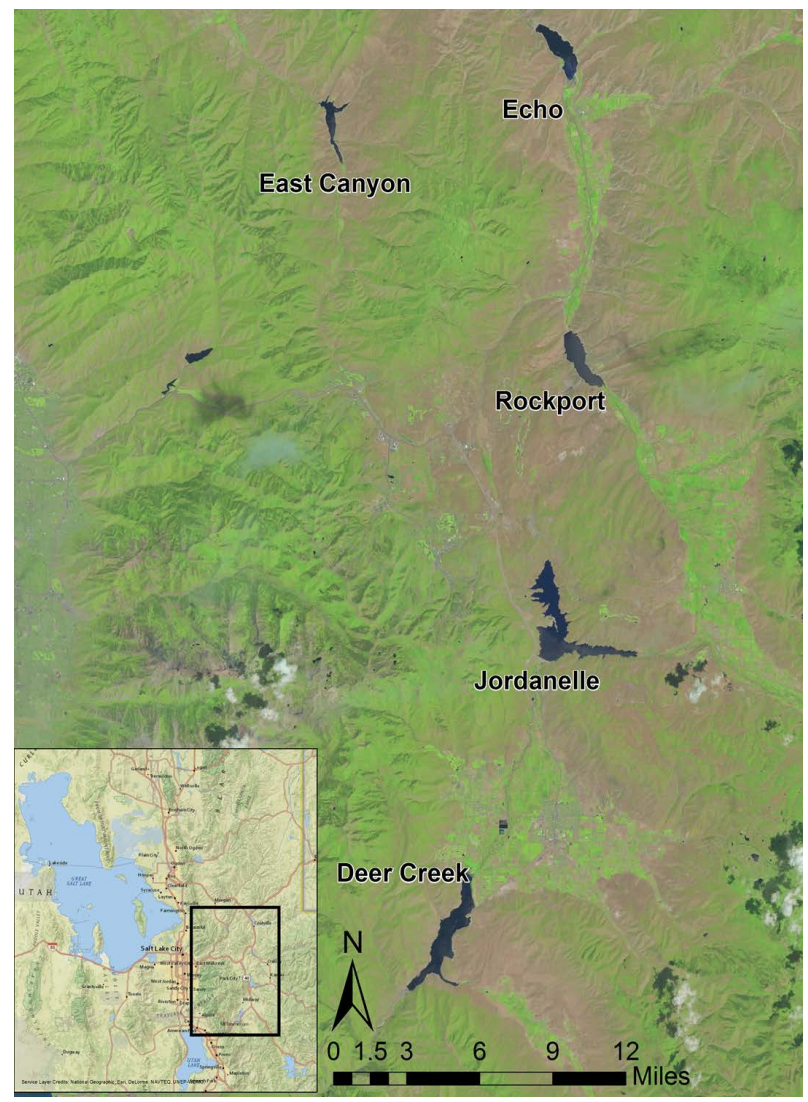

Figure 1. Location of Jordanelle Reservoir near Salt Lake City, Utah in the United States of America. 


\section{Methods}

\section{Data Collection and Processing}

We used Level 1T Landsat 5 and 7 TM products, acquired by the satellite within \pm 24 hours of field samples for model development. Level 1T products provide "systematic radiometric accuracy and geometric accuracy" [9]. We calibrated these images based on sun elevation, date, and sensor type using ENVI version 4.8 (Exelis Visual Information Solutions, Boulder, Colorado). We used a dark-subtraction technique in the ENVI atmospheric correction toolbox to correct for atmospheric interference such as water vapor and aerosols. The dark subtraction atmospheric correction algorithm locates the pixel with lowest reflection value and assumes that response can be attributed to interferences from the atmospheric column. That value is then subtracted from all other pixels, thus correcting or removing the reflectance caused by atmospheric interference. The atmospherically corrected images provided approximate surface reflectance values at a resolution of $30 \mathrm{~m} \times 30 \mathrm{~m}$. All corrections were wavelength dependent.

To develop the remote sensing exploitation models, we obtained field sample data from the Central Utah Water Conservancy District (CUWCD) for both Jordanelle and Deer Creek Reservoirs. These data were collected as part of an ongoing monitoring program of the Provo River System. Measurements for chlorophyll-a were not corrected for pheophytin. Previous studies have demonstrated successful model calibration with windows of \pm 5 days [6] and 7 days [7] however we were able to use near-coincident matches, within the same day or \pm 24 hours, in our calibration to better reflect in-lake conditions at the time of satellite pass-over. We used a total of 26 unique images to develop three sub-seasonal models: spring (April-May), mid-summer (June-July), and latesummer (August-September).We relaxed the requirement slightly to \pm 24 hours of the field sample in the midsummer season in order to increase the number of sample matches as only a few met the same day selection criteria.

\section{Algorithm Development}

To compute the correlation between the field samples and the remote sensing data, we used an average of surface reflectance for each band in the 9 pixels surrounding each field sampling location [10] [11]. This was done to address noise in the remote sensing data and to account for imprecise field locations. We used the following mean-filtering technique to remove noise [10] [11]:

$$
\text { Filtered mean }=\frac{\Sigma_{i}(1.5 * \sigma-\bar{X})<X_{i}<(1.5 * \sigma+\bar{X})}{N}
$$

where $\bar{X}$ is the mean value of the 9 pixels, $\sigma$ is the standard deviation of the 9 pixels, and $N$ is the number of pixels, in this case 9 . This technique removes data that are more the 1.5 standard deviations from the mean. As reservoir surfaces are relatively homogenous, this only removes the noise or speckle present in the data. We used this average surface reflectance with stepwise linear regression to compute the correlation between reflectance and chlorophyll measurements. We needed to determine whether the field-measured data were normally distributed, as normal distribution is a requirement for regression analyses. The results of a lilliefor distribution test indicated that the data for the middle and late summer were not normally distributed, while the spring data were normally distributed and used in the regression analysis. The distributions for the natural log transform of the middle and late summer chlorophyll concentrations, however, were normally distributed and were used in the regression analysis.

We considered all the Landsat bands and band ratios as parameters for the regression. We used a p-value of 0.25 as the threshold for the amount of effect that a parameter must have to be included in the model on a forward step, while a threshold p-value of 0.1 was used to determine whether a parameter should be removed during a backward step. Parameters were added in a stepwise approach until the regression coefficient was improved by less than $5 \%$.

We performed separate regressions for each of the three sub-seasons (spring: April-May; mid-summer: JuneJuly; late-summer: August-September) to account for differences in algae pigmentation and spectral characteristics throughout the growing season (April-September). Each algae population exhibits unique physical properties including buoyancy and pigmentation, making the visible or reflective properties (or spectra) unique to each type of algae [12] [13]. Studies show that diatoms for instance, have lower absorption coefficients than other 
phytoplankton, which means that the reflectance and relation to chlorophyll pigmentation will be different from other phytoplankton [14]. The final algorithms are presented in Equations (2) through 4 and Table 1. It should be noted that the coefficients presented below are region specific, and may not apply to other regions.

$$
\begin{gathered}
\text { Chlorophyll }\left(\frac{\mu \mathrm{g}}{\mathrm{L}}\right)=10.86+0.84\left(X_{1}\right)-0.82\left(X_{2}\right)-9.07\left(X_{3}\right)+0.96\left(X_{4}\right) \\
\log \left(\text { Chlorophyll }\left(\frac{\mu \mathrm{g}}{\mathrm{L}}\right)\right)=1.55-98.17\left(X_{1}\right)+102.92\left(X_{2}\right)-0.44\left(X_{3}\right) \pm 0.26\left(X_{4}\right) \\
\log \left(\text { Chlorophyll }\left(\frac{\mu \mathrm{g}}{\mathrm{L}}\right)\right)=-2.15-36.32\left(X_{1}\right)+1.23\left(X_{2}\right)-1.46\left(X_{3}\right)+0.31\left(X_{4}\right)+6.32\left(X_{5}\right)
\end{gathered}
$$

where $X_{i}$ is a combination of Landsat bands as detailed in Table 1. The regression coefficients for each of the sub-seasonal models are relatively high, at $0.83,0.64$, and 0.91 for the spring, mid, and late summer respectively.

\section{Model Application}

We applied the algorithms to historic Landsat images collected during the growing season from the period of 1993-2012, corresponding to the time frame of when the reservoir was filled and regular monitoring data were available. Figure 2 shows the results of these calculations with the average and maximum estimated chlorophyll shows for each of the three models. The early model results are shown in the top panel, the mid-season model results are shown in the middle panel, and the late-season model results are shown in the bottom panel (Figure 2). While Landsat data is recorded on a 16-day return period, some seasons did not have available imagery data due to cloud cover or haze obstructing view of the reservoir surface (as evidenced by the breaks in the time series in Figure 2).

Figure 3 shows a linearly interpolated time series analysis of the chlorophyll levels. Intermediate peaks highlight the variability between seasons (more clearly illustrated in Figure 2 and the difference in magnitude between spring/mid-summer and late summer chlorophyll levels).

We used linear regression techniques to determine the best-fit lines for the different seasons for trends analysis. We analyzed the trends on a seasonal basis to determine the trends over the 20-year period. We broke the analysis into seasons because a single regression would not describe the trend as well because of seasonal variation and difference in magnitude (the late-summer is often much one or two orders of magnitude higher than the early or mid-season).

In addition to these trends, remote sensing models provide descriptions of the algae distribution throughout the reservoir. Figure 4 demonstrates spatial differences through seasons and throughout the reservoir. The chlorophyll concentration is much higher throughout the entire reservoir in the image from August 22, 2002 (note the difference in scales) while the north arm of the reservoir has lower concentrations. In the May 21, 2003 image however, the north arm has relatively high concentration compared to the northern-most point.

These spatial distribution maps have the potential to identify and target specific areas within a reservoir. For instance the high variability in the north arm and the northernmost tip in May of 2003 may lead to under or overestimated values from point samples. Knowledge of variability and distribution can be used to focus or improve field sampling techniques.

Table 1. Bands and/or band ratios used in sub-seasonal algorithms where $X$ refers to the positions in Equations (2) through (4) and B\# refers to the Landsat bands.

\begin{tabular}{ccccccc}
\hline Sub-season model & $X_{1}$ & $X_{2}$ & $X_{3}$ & $X_{4}$ & $X_{5}$ \\
\hline Spring & B3/B1 & B4/B7 & B5/B4 & B7/B5 & * \\
Mid-summer & B5 & B7 & B2/B4 & B5/B3 & * \\
Late-summer & B1 & B2/B5 & B3/B5 & B4/B7 & B5/B4 \\
\hline
\end{tabular}



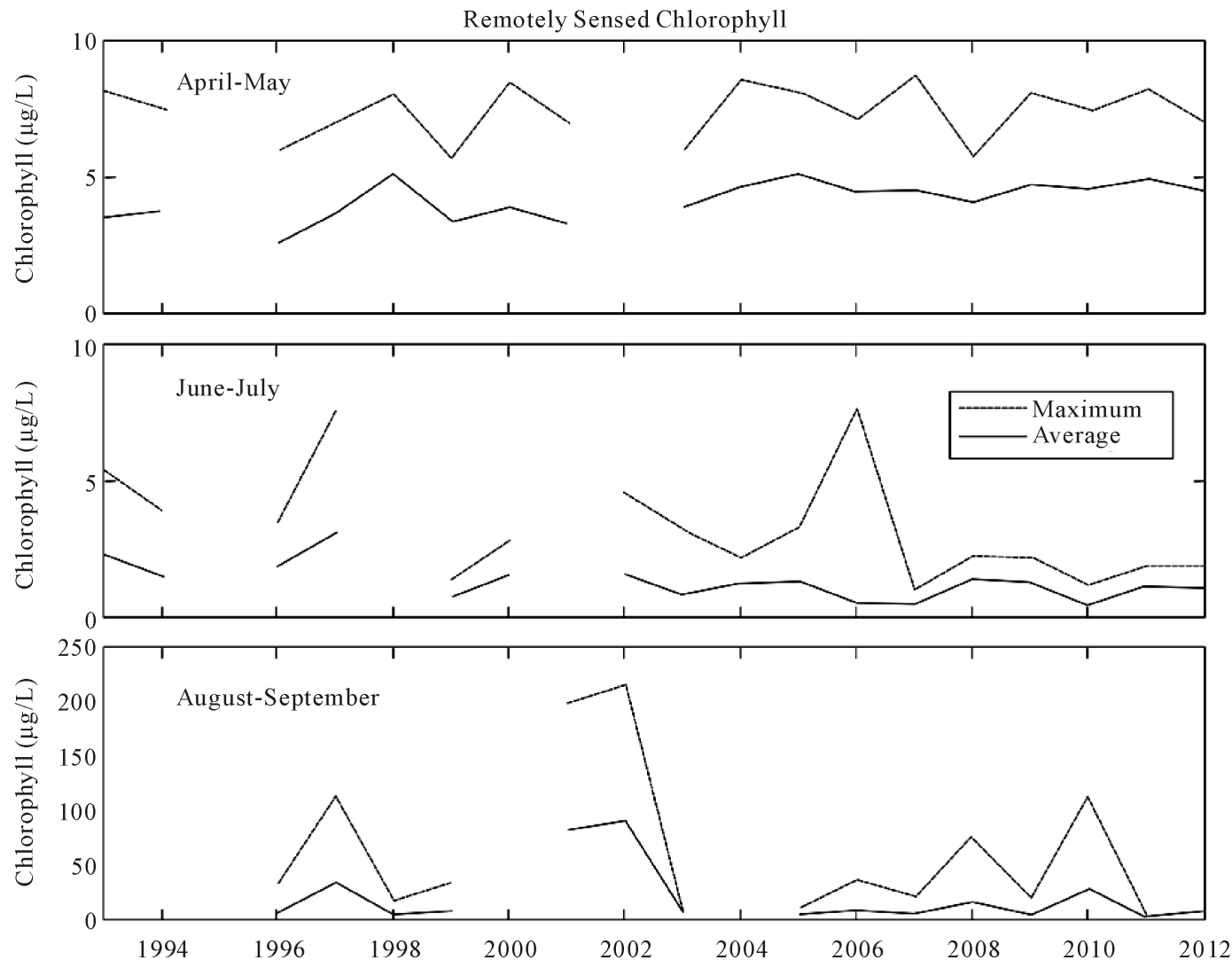

Figure 2. Maximum and average chlorophyll concentration by year and season, note the scale different between the late-summer and other plots. In addition to chlorophyll concentrations, this shows periods where Landsat images were not available.

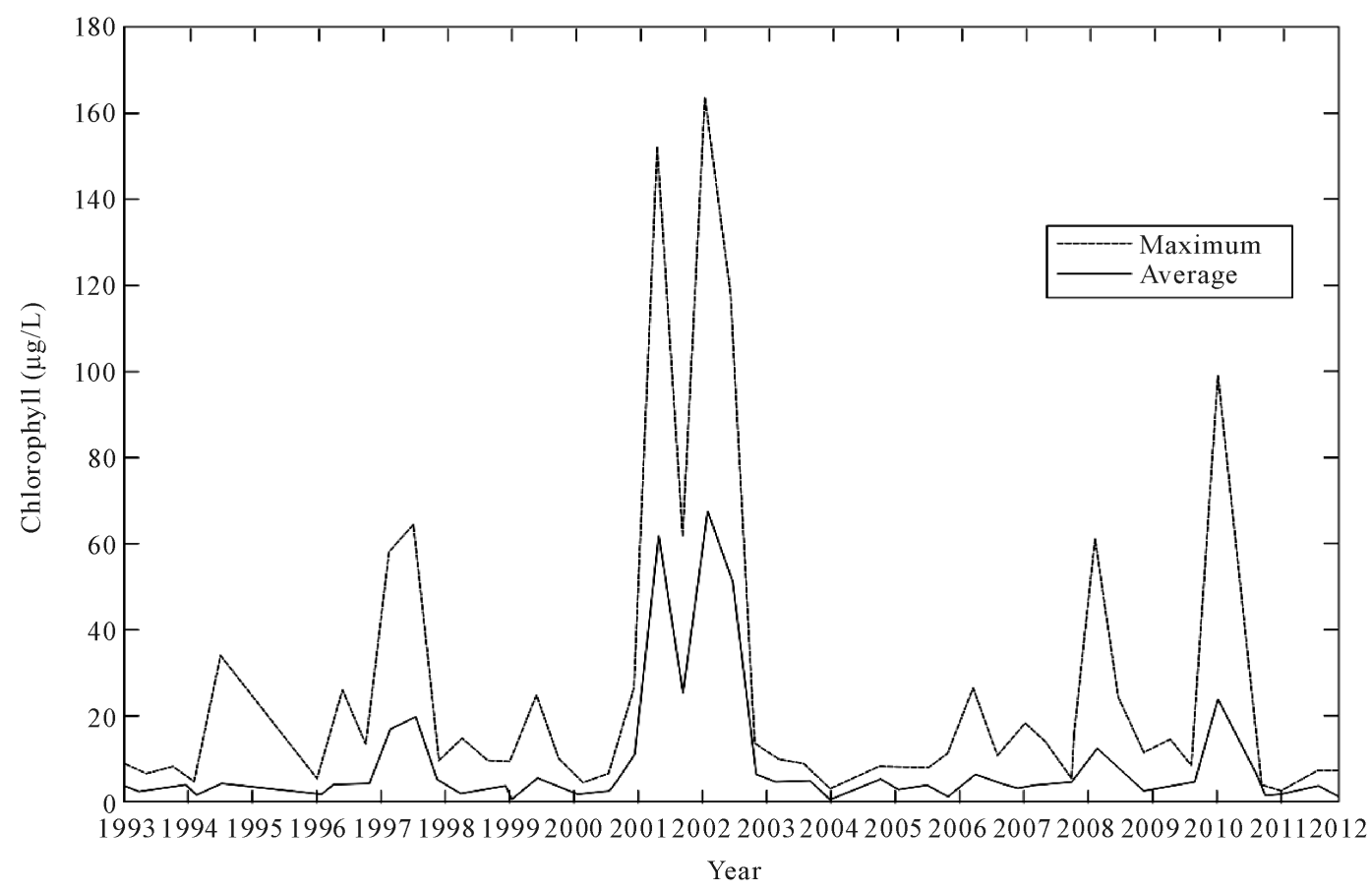

Figure 3. Linearly interpolated time series of chlorophyll-a concentrations from 1993-2012. 


\section{Results}

The trends (Table 2) show that long-term rate-of-change in the early and mid-summer months is small with a slight long-term increase in the spring concentrations with rates of 0.06 and $0.09 \mu \mathrm{g} / \mathrm{L} / \mathrm{year}$ for the average and maximum concentrations, respectively and a corresponding slight long-term decrease in the mid-summer concentrations with rates of $-0 / 07$ and $-0.19 \mu \mathrm{g} / \mathrm{L} /$ year for the average and maximum concentrations, respectively. The late summer months show a relatively large decreasing rate in the average concentration and maximum concentration of $-0.79 \mu \mathrm{g} / \mathrm{L} /$ year and $-2.5 \mu \mathrm{g} / \mathrm{L} / \mathrm{year}$, respectively. The standard deviation also shows a decreasing trend in the estimated chlorophyll on the surface as measured by remotely sensed data during the late summer months. This is an important measure of the algal biomass processes in the reservoir because a decrease in standard deviations indicates a decrease in variability across the reservoir. As variability decreases spatially, the specific location of field sampling sites becomes less critical.

\section{Discussion}

While there is significant variation in average and maximum chlorophyll content over the 20 year life of Jordanelle Reservoir the mid-summer and late-summer values for both the average and the maximum have been decreasing, with the maximum values decreasing at a faster rate than the average. One interpretation of the maximum value is an indication of an algae bloom at some location in the reservoir. Since the maximum is decreasing more rapidly than the average, this indicates that the occurrence of algae blooms might also be decreasing though more study would be required to ascertain this fact. While the mid-summer average value is decreasing, the rate is very low, $-0.07 \mu \mathrm{g} / \mathrm{L} /$ year, which is on the order of the standard deviation for the data. This low value implies that mid-summer conditions do not have a significant trend over the 20-year time period. As opposed to the mid- and late-summer values, spring average and maximum values have both been increasing slightly over the 20-year time period, at rates of 0.06 and $0.09 \mu \mathrm{g} / \mathrm{L} /$ year, respectively. These data also have a low standard deviation representing less variability than the later seasons.

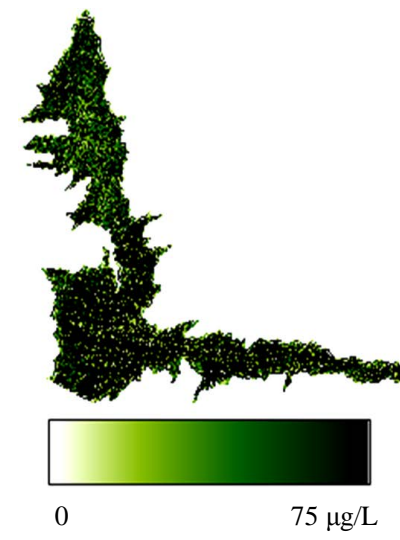

(a)

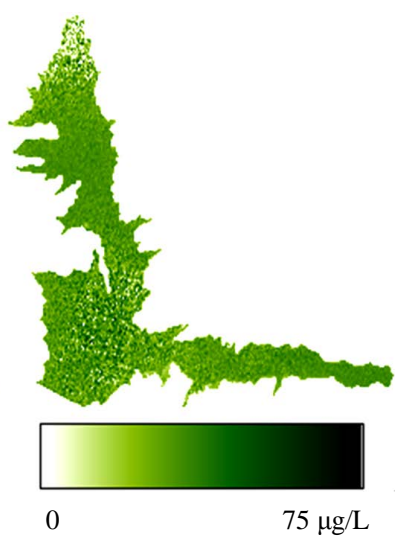

(b)

Figure 4. Spatial distribution of algae in Jordanelle Reservoir. (a) August 22, 2002; (b) May 21, 2003.

Table 2. Trends in the average, maximum and standard deviation of chlorophyll-a concentrations by season from 19932012.

\begin{tabular}{cccc}
\hline Sub-season model & $\begin{array}{c}\text { Average } \\
(\mu \mathrm{g} / \mathrm{L} / \mathrm{year})\end{array}$ & $\begin{array}{c}\text { Maximum } \\
(\mu \mathrm{g} / \mathrm{L} / \mathrm{year})\end{array}$ & $\begin{array}{c}\text { Standard } \\
\text { deviation }\end{array}$ \\
\hline Spring & 0.06 & 0.09 & 0.02 \\
Mid-summer & -0.07 & -0.19 & -0.05 \\
Late-summer & -0.79 & -2.50 & -0.81 \\
\hline
\end{tabular}


While the data show trends, examination of Figure 3 shows that there have been periods of both very high and relatively low algae content in Jordanelle. For example, the time period from 2001 to 2003 exhibits large average and maximum concentrations, this is followed by a period of relatively low concentrations from 2003 through 2006. Given these large changes in algae conditions, the most likely drivers are weather conditions as nutrient inflows from regular processes do not vary by these amounts. One of the strengths of using historical remote sensing data is to identify these types of anomalies in the historic record. Once these anomalies time periods have been identified, they can be studied to determine if a cause can be ascertained. If so, this information can be used by reservoir managers to anticipate reservoir conditions and manage resources to mitigate and potential adverse effects.

\section{Conclusion}

Satellite data show algal biomass to be decreasing in the late summer months, as demonstrated by a decreasing trend in average chlorophyll as measured on the surface by remotely sensed data, though on any given year concentrations can be higher. In addition to decreases in both the average concentration and maximum concentration, the standard deviation of algal concentrations across the reservoir in the late-summer is decreasing, indicating less variability. This means that field sample locations are less critical and that smaller, local blooms are less evident in the satellite record. The satellite data show that algal biomass in the spring and mid-summer has been relatively constant over the 20-year study period, though slight trends are evident. Remote sensing analysis offers additional measures of algae distribution and spatial variability through visual analysis (distribution maps) and statistics (spatial averages and standard deviation).

\section{References}

[1] Ask Landsat (2013) http://landsat.usgs.gov

[2] Prowse, G. and Talling, J. (1958) The Seasonal Growth and Succession of Plankton Algae in the White Nile. Limnology and Oceanography, 3, 222-238. http://dx.doi.org/10.4319/lo.1958.3.2.0222

[3] Castenholz, R.W. (1960) Seasonal Changes in the Attached Algae of Freshwater and Saline Lakes in the Lower Grand Coulee, Washington. Limnology and Oceanography, 5, 1-28. http://dx.doi.org/10.4319/lo.1960.5.1.0001

[4] Stadelmann, T.H., Brezonik, P.L. and Kloiber, S. (2001) Seasonal Patterns of Chlorophyll a and Secchi Disk Transparency in Lakes of East-Central Minnesota: Implications for Design of Ground- and Satellite-Based Monitoring Programs. Lake and Reservoir Management, 17, 299-314. http://dx.doi.org/10.1080/07438140109354137

[5] Olmanson, L.G., Bauer, M.E. and Brezonik, P.L. (2008) A 20-Year Landsat Water Clarity Census of Minnesota’s 10,000 Lakes. Remote Sensing of Environment, 112, 4086-4097. http://dx.doi.org/10.1016/j.rse.2007.12.013

[6] Brezonik, P., Menken, K.D. and Bauer, M. (2005) Landsat-Based Remote Sensing of Lake Water Quality Characteristics, including Chlorophyll and Colored Dissolved Organic Matter (CDOM). Lake and Reservoir Management, 21, 373-382. http://dx.doi.org/10.1080/07438140509354442

[7] Fuller, L.M., Aichele, S.S. and Minnerick, R.J. (2004) Predicting Water Quality by Relating Secchi-Disk Transparency and Chlorophyll a Measurements to Satellite Imagery for Michigan Inland Lakes, August 2002. US Department of the Interior, US Geological Survey.

[8] UDEQ (2004) Jordanelle Reservoir Lake Report, in Lake Reports. Utah Department of Environmental Quality.

[9] USGS (2014) Landsat Missions. Ask Landsat 2013.

[10] Bailey, S.W. and Werdell, P.J. (2006) A Multi-Sensor Approach for the On-Orbit Validation of Ocean Color Satellite Data Products. Remote Sensing of Environment, 102, 12-23. http://dx.doi.org/10.1016/j.rse.2006.01.015

[11] Johnson, R., et al. (2013) Three Improved Satellite Chlorophyll Algorithms for the Southern Ocean. Journal of Geophysical Research: Oceans, 118, 3694-3703.

[12] Cullen, J.J. (1982) The Deep Chlorophyll Maximum: Comparing Vertical Profiles of Chlorophyll a. Canadian Journal of Fisheries and Aquatic Sciences, 39, 791-803. http://dx.doi.org/10.1139/f82-108

[13] Morel, A. and Berthon, J.F. (1989) Surface Pigments, Algal Biomass Profiles, and Potential Production of the Euphotic Layer: Relationships Reinvestigated in View of Remote-Sensing Applications. Limnology and Oceanography, 34, 1545-1562. http://dx.doi.org/10.4319/lo.1989.34.8.1545

[14] Sathyendranath, S., et al. (2004) Discrimination of Diatoms from Other Phytoplankton Using Ocean-Colour Data. Marine Ecology Progress Series, 272, 59-68. http://dx.doi.org/10.3354/meps272059 
Scientific Research Publishing (SCIRP) is one of the largest Open Access journal publishers. It is currently publishing more than 200 open access, online, peer-reviewed journals covering a wide range of academic disciplines. SCIRP serves the worldwide academic communities and contributes to the progress and application of science with its publication.

Other selected journals from SCIRP are listed as below. Submit your manuscript to us via either submit@scirp.org or Online Submission Portal.
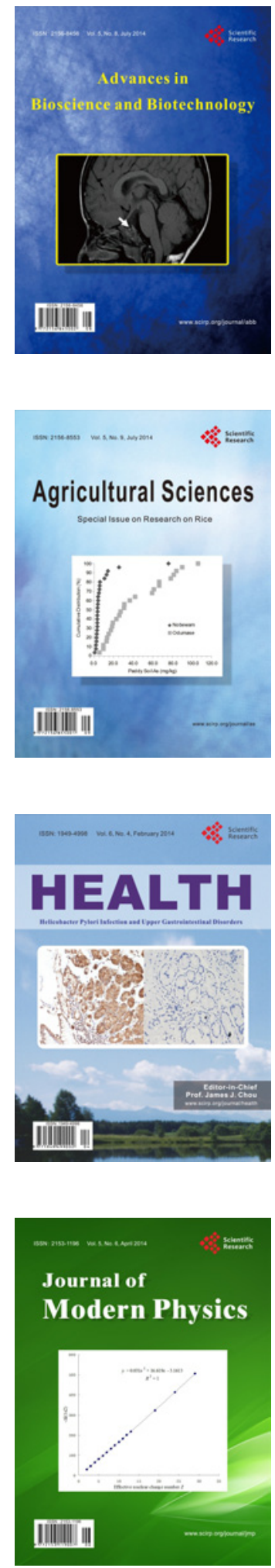
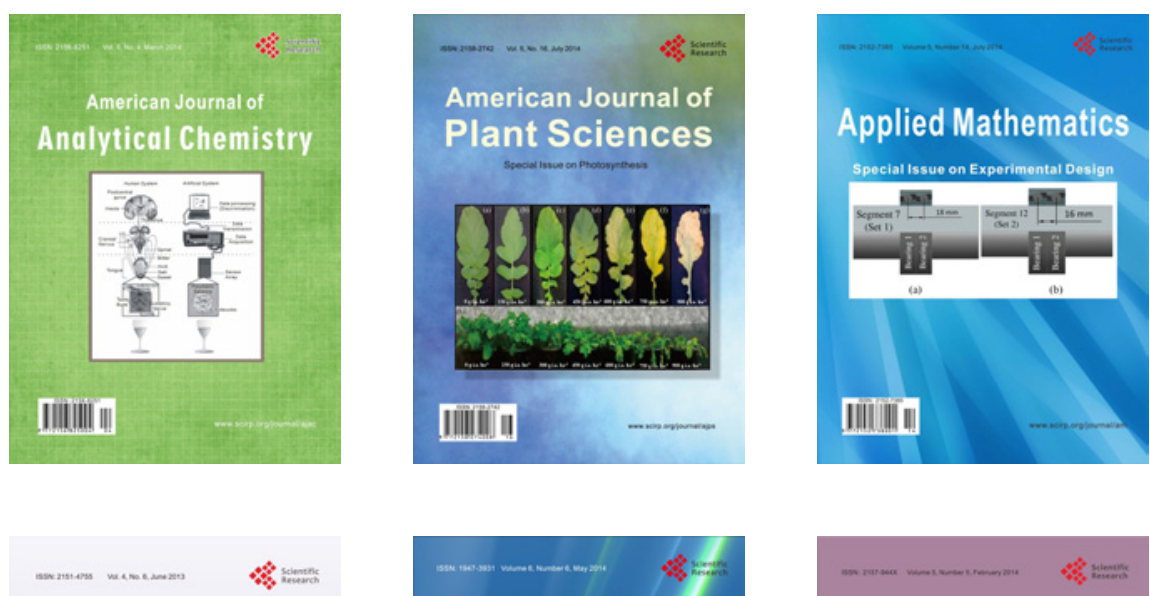

Creative Education
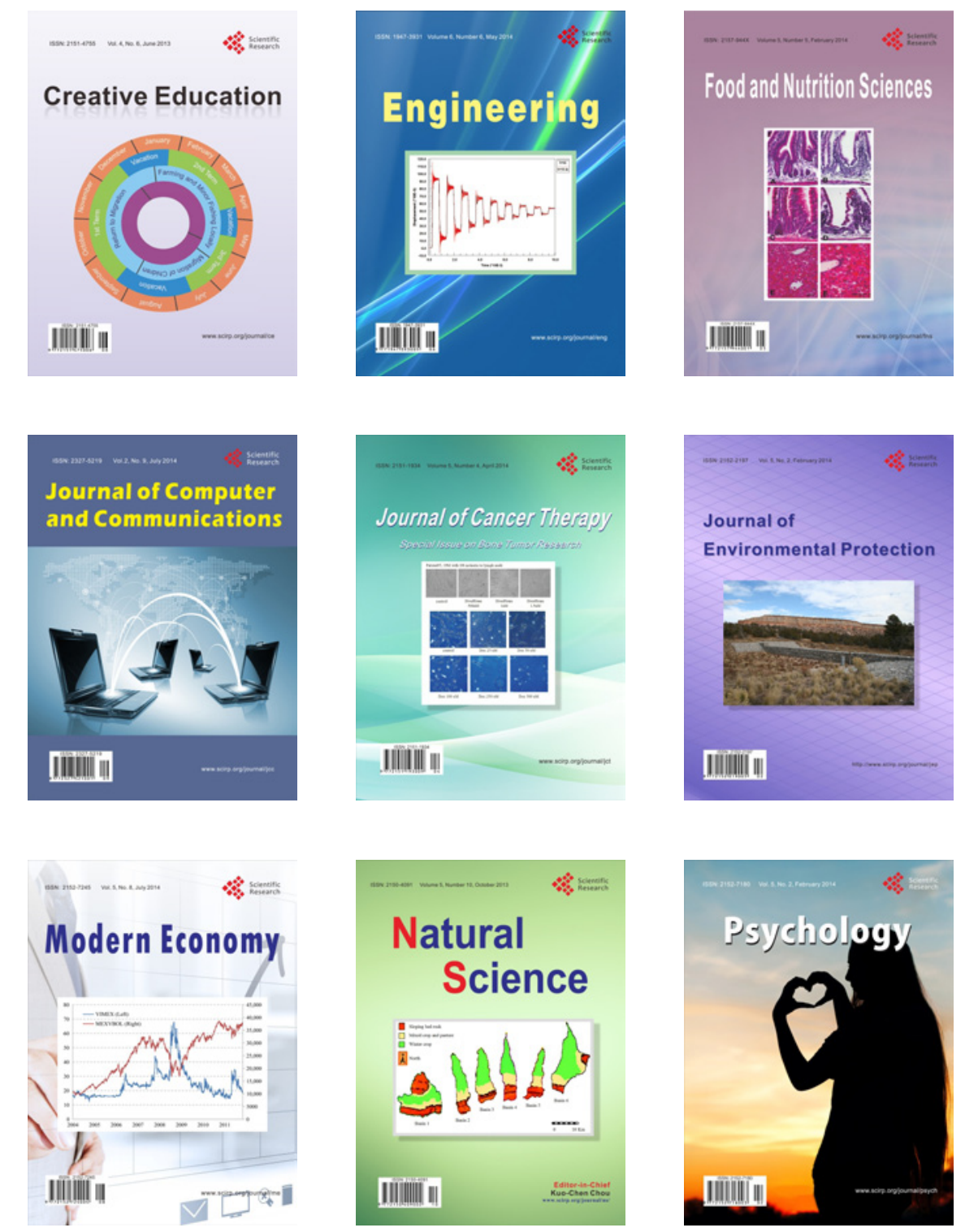